\title{
Prothrombin Complex Concentrates to Treat Coagulation Disturbances: An Overview With a Focus on Use in Infants and Children
}

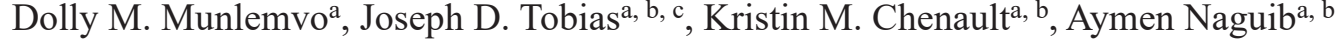

\begin{abstract}
Various factors may lead to coagulation disturbances following cardiopulmonary bypass and surgery for congenital heart disease. In addition to the risks associated with the administration of allogeneic blood products, persistent disturbances in coagulation function and ongoing bleeding may lead to prolonged surgical times, hemodynamic alterations, intracranial hemorrhage, and even mortality. In most clinical scenarios, coagulation disturbances are treated by targeted blood product therapy including fresh frozen plasma, platelet transfusions, or the administration of cryoprecipitate. When routine blood product therapy fails, coagulation adjuncts such as activated recombinant factor VII or prothrombin complex concentrates (PCCs) may be an option to rapidly replenish depleted coagulation factors and correct coagulation disturbances. The PCC formulations including three-factor PCC, four-factor PCC, and factor eight-inhibitor bypass activator (FEIBA) have been used mainly in the adult population with sporadic case series and anecdotal reports in the pediatric population. The following manuscript discusses the various PCC products available for clinical use, reviews previous reports of their use in infants and children with an emphasis on their role following surgery for congenital heart disease, and outlines their potential role in these clinical scenarios.
\end{abstract}

Keywords: Prothrombin complex concentrates; Congenital heart disease; Coagulation factors; Cardiopulmonary bypass; Allogeneic blood products; Transfusions

\section{Introduction}

Coagulation disturbances and the resulting blood transfusion

Manuscript submitted December 6, 2021, accepted January 12, 2022

Published online January 29, 2022

aDepartment of Anesthesiology and Pain Medicine, Nationwide Children's Hospital, Columbus, OH, USA

bepartment of Anesthesiology and Pain Medicine, The Ohio State University, Columbus, OH, USA

${ }^{\mathrm{c} C o r r e s p o n d i n g ~ A u t h o r: ~ J o s e p h ~ D . ~ T o b i a s, ~ D e p a r t m e n t ~ o f ~ A n e s t h e s i o l o g y ~ a n d ~}$ Pain Medicine, Nationwide Children's Hospital, Columbus, OH 43205, USA. Email: Joseph.Tobias@nationwidechildrens.org

doi: https://doi.org/10.14740/cr1342 requirements in pediatric patients undergoing cardiac surgery using cardiopulmonary bypass (CPB) are associated with the potential for perioperative morbidity and adverse postoperative outcomes [1]. Adverse effects related to the administration of allogeneic blood products include the transmission of infectious diseases, immunologic reactions, transfusion-related acute lung injury, prolonged mechanical ventilation, and increased length of stay in the intensive care unit (ICU) and the hospital $[2,3]$. The need for allogeneic blood products is increased during surgery for congenital heart disease (CHD) and the use of CPB in neonates and infants. Hemodilution imposed by the CPB circuit compared to the lower overall blood volume of a neonate or infant is just one of the many factors responsible for coagulation disturbances in this patient population. The circuit volume may be as much as double the infant's blood volume with the resulting dilution of platelets and coagulation factors. The disparity between the CPB circuit size also increases the exposure of the blood components to the larger circuit surface area, resulting in increased fibrinolysis, activation of the complement cascade, and stimulation of an inflammatory reaction. In addition, neonates and infants are further at risk for postoperative coagulation disturbances due to the developmental immaturity of their coagulation system, the complexity of the surgical repair, and the intraoperative use of more profound hypothermia [4]. Additionally, the severity of the coagulopathy is greater in children with cyanotic CHD, with studies demonstrating an increased need for blood products including fresh frozen plasma (FFP) and platelets compared to their acyanotic counterparts [5].

The management of coagulation disturbances following CPB and surgery for CHD can be challenging, frequently requiring more than just conventional blood products (FFP, platelets, and cryoprecipitate). Although factor concentrates such as recombinant factor VIIa (rFVIIa) and prothrombin complex concentrates (PCCs) including three-factor PCC (3F$\mathrm{PCC}$ ), four-factor PCC (4F-PCC), and factor eight-inhibitor bypass activator (FEIBA) were introduced initially to treat patients with hemophilia A, they are currently administered offlabel in patients with bleeding after CPB [6-8]. While the majority of the data come from adult patients or small case series of pediatric patients, anecdotal evidence suggests that these agents may be effective in reducing bleeding and the need for allogeneic blood products. However, as these factors augment thrombin and fibrin formation, their possible complications cannot be overlooked and must also be considered. Thrombo- 
Table 1. Factor Composition of Various Coagulation Adjuncts and Concentrates

\begin{tabular}{lll}
\hline Factor concentrate & Brand names & Composition \\
\hline $\begin{array}{l}\text { Three-factor PCC } \\
\text { Four-factor PCC }\end{array}$ & Profilnine $^{\circledR}$ SD, Bebulin ${ }^{\circledR}$ & Factors II, IX and X \\
& $\begin{array}{l}\text { Beriplex }^{\circledR}, \text { Kcentra }^{\circledR}, \text { Confidex }^{\circledR}, \\
\text { Octaplex }^{\circledR}, \text { and Prothromblex }\end{array}$ & Factors II, VII, IX and X; protein \\
Activated PCC & FEIBA-NFTM & Frotein S, and heparin \\
Recombinant factor VIIa & Novoseven $^{\circledR}$ & Factors II, VIIa, IX, Xa; protein C \\
Fibrinogen concentrate & RiaSTAP $^{\circledR}$ & Factor VIIa \\
\hline
\end{tabular}

PCC: prothrombin complex concentrate.

embolic events are the most often encountered complications, raising concerns regarding the possible imbalance between procoagulant and anticoagulant factors while correcting the coagulopathy. Due to the paucity of data regarding evidence of the benefit of these agents, the Congenital Cardiac Anesthesia Society task force and the Network for Advancement of Patient Blood Management (NATA) task force recently recommended that activated factor VIIa or PCCs not be administered during cardiac surgery in infants and children unless it is a part of a clinical trial or to treat extreme bleeding despite the use of standard blood product therapy [9]. The current manuscript reviews the introduction of PCCs into clinical practice, and discusses previous reports regarding their use in infants and children with a focus on surgery for CHD. A systematic search of PubMed ${ }^{\circledR}$ was conducted using the search terms listed as keywords for the manuscript. The abstracts from the publications were reviewed and those pertinent to the subject matter were included for further review. Additionally, the reference lists of these publications were reviewed to ensure that all appropriate manuscripts had been identified.

\section{PCCs: Initial Production and Clinical Use}

The coagulation factors (I-XIII) are present in varying physiologic concentrations in human plasma. However, when used for therapeutic purposes to treat bleeding in various clinical scenarios, higher concentrations are frequently required necessitating the need to transfuse large and often impossible volumes of FFP. With both inherited and acquired factor deficiencies resulting in clinically significant coagulation disturbances, pharmacologic doses of the various coagulation factors may be needed. Cryoprecipitate was one of the first pooled products with concentrations of various factors far above that available in FFP. Historically, it was first used clinically to treat patients with factor deficiencies, initially hemophilia A [10]. As cryoprecipitate is a pooled product that does not undergo pathogen inactivation, its administration carries the risk of the transmission of viral pathogens. The next innovation in the therapeutic use of specific coagulation factors was the production of virally inactivated plasma-derived coagulation factor concentrates. These latter products included single coagulation factor concentrates (such as factor VIII concentrates for the treatment of hemophilia A and factor IX concentrates for the treatment of hemophilia B). The development and refinement of recombinant technology subsequently led to the availability of high concentration products of single coagulation factors including factor VII, VIII, IX, or XIII which not only proved effective in replacing deficient factors, but also eliminated the threat of the transmission of viral diseases including hepatitis and human immunodeficiency virus (HIV). Although these products have been licensed and used clinically primarily for the treatment of inherited or acquired hemophilia, the use of specific products such as rFVIIa was extended to off-label indications for the treatment of coagulopathy and bleeding due to various pathologic states including following surgery for CHD [11, 12]. However, the lack of formal prospective studies has limited the ability to arrive at firm recommendations regarding its use for this clinical indication $[8,13]$.

PCCs are produced through ion-exchange chromatography using the cryoprecipitate supernatant of large plasma pools following the removal of anti-thrombin and factor XI $[10,11]$. Variations in the ion-exchangers during the processing technique can produce products with either three (factors II, IX and X) or four (factors II, VII, IX and X) factors. Although the specific components in the various 4F-PCCs varies somewhat depending on the manufacturer, these concentrates all contain therapeutic concentrations of the vitamin K-dependent coagulation factors (II, VII, IX, and X). To prevent activation of these factors, most PCCs contain varying concentrations of heparin in addition to varying concentrations of the naturally occurring anti-coagulant proteins (protein $\mathrm{C}$, protein $\mathrm{S}$, and anti-thrombin III (AT-III)). The 3F-PCCs differ in that they do not contain therapeutic levels of factor VII, containing only factors II, IX, and X. All PCCs undergo at least one step of viral reduction or elimination such as solvent detergent treatment or nanofiltration.

PCCs were first used clinically in patients with hemophilia A and B to replenish factor IX, especially in patients with inhibitors to factor VIII [14]. Hence dosing of these factors is based on the international unit (IU) of factor IX present in these concentrates. Although the majority of PCC formulations contain inactivated factors, factor eight-inhibitor bypassing activity (FEIBA ${ }^{\mathrm{TM}}$; Baxter Healthcare Corporation, Westlake Village, $\mathrm{CA}$ ) is the only activated PCC available in the United States of America [13, 15]. FEIBA contains factor VIIa and factor Xa as well as factors FII and FIX.

When considering the various PCCs available for clinical use, they can be separated into 3F-PCCs, 4F-PCCs, and PCCs with activated factors such as FEIBA. Availability varies according to country of practice. A list of some of the clinically available factor concentrates is presented in Table 1. In addi- 
tion to the different procoagulant components in each of these PCCs, there are added anticoagulants that prevent the activation of the coagulation factors when these preparations are diluted with sterile water ahead of its administration. For example, KCentra ${ }^{\circledR}$ (CSL Behring, USA), a 4F-PCC, contains trace amounts of protein $\mathrm{C}$ and $\mathrm{S}$ in addition to AT-III and heparin. Bebulin ${ }^{\circledR}$ (Baxter Healthcare, Bloomington, IN) is a 3F-PCC containing heparin. FEIBA ${ }^{\mathrm{TM}}$ (Baxter Healthcare, Bloomington, IN) is the activated form of a $4 \mathrm{~F}-\mathrm{PCC}$ containing activated factor VII in addition to protein $\mathrm{C}$ as an anticoagulant.

PCCs increase the concentration of the vitamin K-dependent coagulation factors in the blood, augment the amplification phase of coagulation, and may thereby be effective in correcting coagulation disturbances in various clinical scenarios $[11,15$, 16]. Although initially used for replacement therapy in patients with congenital factor deficiencies (hemophilia), they have more recently been shown to be the preferred agent for reversal of coagulation dysfunction in patients receiving vitamin $\mathrm{K}$ antagonists such as coumadin who present for emergent surgery or with bleeding complications [17]. In clinical practice, there may be theoretical and clinical advantages of the 4F-PCCs versus the 3F-PCCs for reversal of oral vitamin K antagonists. The British Committee for Standards in Hematology has identified PCCs as being preferred over FFP for reversing anticoagulation due to vitamin $\mathrm{K}$ antagonists in urgent and emergent situations such as major bleeding $[17,18]$. In 2013, Kcentra ${ }^{\circledR}$ received approval from the United States Food and Drug Administration (FDA) for the reversal of anticoagulation related to vitamin $\mathrm{K}$ antagonists in adults with acute major bleeding episodes. Per the manufacturer's recommendation, Kcentra ${ }^{\circledR}$ dosing in this clinical scenario is based on the international normalized ratio (INR) with a dose of 25 units $/ \mathrm{kg}$ (maximum dose of 2,500 units), 35 units/ $\mathrm{kg}$ (maximum dose of 3,500 units), or 50 units $/ \mathrm{kg}$ (maximum dose of 5,000 units) for an INR value of $2-4,4-6$, and more than 6 , respectively. Currently, only 4F-PCCs are recommended for the reversal of vitamin $\mathrm{K}$ antagonists. In these trials, various risk factors for failure (mortality) have been identified including body mass index $\geq 30 \mathrm{~kg} / \mathrm{m}^{2}$, anemia, intracranial bleeding, the requirement for allogeneic blood products, hypotension, and the need for mechanical ventilation with the latter two carrying the greatest risk [19]. Although 3F-PCCs can be used to reverse the anticoagulant effect of warfarin, the lack of factor VII in these preparations makes them less effective in achieving this goal, since factor VII has a profound in vitro effect in normalizing the INR [20, 21].

\section{Preliminary Experience in Adult Patients}

Given their non-specific effect on coagulation function and success in treating patients with bleeding related to hemophilia or the use of vitamin K antagonists, the PCCs were subsequently used in open label trials in other clinical scenarios to treat coagulation disturbances and clinically significant bleeding in adults that was refractory to conventional blood product therapy including trauma, adult cardiac surgery, liver surgery, and obstetrical bleeding $[15,16,22]$. In one of the initial reports, Bruce and Nokes retrospectively presented their experience with the ad- ministration of PCC to a cohort of 24 adult patients with bleeding related to surgery including cardiac procedures, and bleeding related to the administration of vitamin $\mathrm{K}$ antagonists [22]. A majority of the patients $(83.3 \%)$ received no more than 1,500 IU of Beriplex P/N 500. The authors reported a significant reduction in administration of other blood products during the 24 $\mathrm{h}$ after PCC administration with partial or complete hemostasis achieved in 14 of 18 patients $(77.8 \%)$. Although mortality was high in this critically ill cohort of patients $(50 \%)$, two-thirds of the deaths were considered unrelated to bleeding. No thrombotic complications or adverse drug reactions were observed. The authors concluded that their study emphasized the value of PCC in reversing the effects of oral anticoagulant therapy in bleeding patients as well as in patients undergoing cardiac and other surgical procedures. They suggested the need for future studies and the potential utility of PCC as a substitute for conventional blood products including FFP.

The potential utility of the PCCs in trauma and other scenarios with bleeding related to a dilutional coagulopathy is further supported by animal studies [23-26]. In these studies, PCCs have been shown to correct coagulation function, improve hemostasis, and decrease bleeding with a reduction in mortality. The efficacy and outcomes in these studies have been shown to be superior to treatment with FFP or rFVIIa. Following traumatic injury, coagulopathy is a component of the lethal triad, along with acidosis and hypothermia, which is responsible for poor outcomes $[27,28]$. During damage-control resuscitation, massive transfusion protocols initiated to replace large blood losses can lead to this lethal triad and subsequent mortality.

Various authors have reported preliminary retrospective data regarding the use of PCCs in adults with trauma including associated traumatic brain injury (TBI) $[29,30]$. In a retrospective 4-year study of 85 adults with traumatic injuries including TBI, 64 patients received PCC and 21 patients received rFVIIa. PCCs were used more commonly in patients who were receiving chronic anticoagulation with coumadin. The administration of PCCs resulted in a reduction in the transfusion of packed red blood cells and FFP. There was no statistically significant difference in the craniotomy rate or the mean time to intervention between patients receiving PCC versus rFVIIa. Mortality was lower in the PCC group compared with rFVIIa (47\% vs. $67 \%, \mathrm{P}=0.02)$ as was the average treatment cost per patient $(\$ 1,007$ versus $\$ 5,757, \mathrm{P}<0.01)$. Thromboembolic events were reported in only one patient from either cohort group, a patient who had received rFVIIa. The authors concluded that PCC is safe and effective for treating coagulopathy in trauma and TBI patients with a reduction in both mortality and cost when compared to rFVIIa [29]. They suggested that PCC should be considered as an effective therapy to treat both acquired and induced coagulation disturbances in patients with TBI with or without prehospital coumadin use.

Additional investigations have reported similar outcomes regarding PCC use in adult trauma patients (Table 2) [29-33]. When comparing PCC and FFP to FFP alone in a propensitymatched cohort of 252 adult trauma patients, PCC administration resulted in a faster correction of the INR (average of 394 versus $1,050 \mathrm{~min})$, a reduction in pack red blood cell requirements (6.6 versus 10 units), a reduction in FFP use (2.8 versus 3.9 units), and a decline in mortality [30]. PCC and FFP use was associated 
Table 2. Selected Reports of PCC Use in Adults With Traumatic Injury

\begin{tabular}{|c|c|c|}
\hline Author and reference & Study design and cohort & Outcomes \\
\hline Joseph et al [29] & $\begin{array}{l}\text { Retrospective study including } 85 \text { TBI patients } \\
\text { in a level-1 trauma center who received } \\
\text { PCC ( } 64 \text { patients) or rFVIIa ( } 21 \text { patients). }\end{array}$ & $\begin{array}{l}\text { Mortality rate was lower in the PCC group compared with rFVIIa. } \\
\text { PCC was an effective treatment for coagulopathy, reducing } \\
\text { the resources needed and costs when compared to rFVIIa. }\end{array}$ \\
\hline Joseph et al [30] & $\begin{array}{l}\text { Retrospective study with propensity-scoring } \\
\text { matching of } 252 \text { trauma patients with INR } \\
\geq 1.5 \text { over a } 2 \text {-year period, divided in two } \\
\text { groups: PCC and FFP versus FFP alone. }\end{array}$ & $\begin{array}{l}\text { PCC use was associated with a more rapid correction } \\
\text { of the INR, reduction in requirement for packed red } \\
\text { blood cells and FFP, and decreased mortality ( } 23 \% \text { vs. } \\
28 \% ; \mathrm{P}=0.04) \text { when compared to FFP alone. }\end{array}$ \\
\hline Joseph et al [32] & $\begin{array}{l}\text { Four-year retrospective analysis of } 88 \\
\text { patients with devastating gunshot wounds to } \\
\text { the brain. Thirteen patients had coagulation } \\
\text { disturbances at the time of admission. }\end{array}$ & $\begin{array}{l}\text { Ten patients received PCCs. Mean INR before PCC administration } \\
\text { was } 2.01 \pm 0.7 \text { and decreased to } 1.1 \pm 0.7 \text { after administration. } \\
\text { Correction of coagulopathy was attained in seven of } 10 \text { patients } \\
(70 \%) \text {. Of these seven patients, consent for donation was } \\
\text { obtained in six, resulting in } 19 \text { solid organs being procured. }\end{array}$ \\
\hline
\end{tabular}

PCC: prothrombin complex concentrate; INR: international normalized ratio; FFP: fresh frozen plasma; rFVIla: recombinant activated factor VII; TBI: traumatic brain injury.

with a higher cost of therapy, but an overall lower transfusion cost. The same investigators demonstrated the potential clinical advantage of 4F-PCC compared to 3F-PCC in adult trauma patients noting a more rapid INR correction and a reduction in transfusion requirements with no difference in thromboembolic events or hospital costs [31]. Additional clinical work from these investigators has demonstrated other benefits of rapid coagulation function correction with PCCs in adult patients with TBI, including a more rapid progression to the operating room for patients requiring craniotomy and the ability to rapidly correct coagulation defects and perhaps facilitate organ donation $[32,33]$.

Various study designs have also evaluated the efficacy of PCCs in adult cardiac surgery [34-37]. In a meta-analysis of 861 adult patients undergoing cardiac surgery, PCC was more effective than FFP in reducing perioperative blood transfusion with no additional risks of thromboembolic events or other adverse reactions [38]. Although patients receiving PCCs had a significant reduction in red blood cell transfusions, no differences were observed between the groups for re-exploration for bleeding, chest tube output at $24 \mathrm{~h}$, hospital mortality, stroke, thromboembolic events, and acute kidney injury. The authors concluded that randomized controlled trials were needed to establish safety and efficacy data.

\section{Preliminary Experience in Pediatric Patients}

As in the adult population, the clinical applications of PCCs in children began with their use in patients with hemophilia A and inhibitors against factor VIII [39]. Prophylactic use of PCCs has been shown to prevent hemarthrosis without an increased risk of thromboembolic events. Others have reported the use of PCC in infants and children in the non-hemophilia population (Table 3) [40-43]. Karube et al retrospectively reviewed their experience with the use of a 4F-PCC to treat bleeding related to various etiologies, most likely traumatic injury [40]. The study cohort included 24 patients, ranging in age from 2 months to 23 years. Only two patients were receiving chronic therapy with anticoagulant medications (warfarin or enoxaparin). Twenty-nine doses of 4F-PCC were administered to the 24 patients. The median dose was 27 units $/ \mathrm{kg}$ (range 16 - 54 units $/ \mathrm{kg}$ ). Three patients received more than one dose of $4 \mathrm{~F}-\mathrm{PCC}$. The primary indication for PCC administration was perioperative and periprocedural correction of coagulopathy followed by hemorrhage with refractory coagulopathy. 4F-PCC effectively decreased the INR, corrected abnormalities on the rotational thrombo-elastogram (ROTEM), and subjectively controlled bleeding. Thrombotic complications were noted in five patients $(20.8 \%)$ who were diagnosed with deep venous thrombosis associated with a central venous catheter in the femoral vein. The median time from 4FPCC administration to diagnosis of deep vein thrombosis (DVT) was 10 days (range from 6 to 30 days) and therefore the authors could not prove a causal relationship.

Additional anecdotal and retrospective data have suggested other clinical scenarios in which PCCs may be effective in infants and children. As noted previously, PCCs are FDAapproved for reversal of anticoagulation related to vitamin $\mathrm{K}$ antagonists in adults. In a retrospective study, PCCs were administered to 16 infants and children, ranging in age from 23 days to 16 years, to control postoperative bleeding or for reversal of vitamin $\mathrm{K}$ antagonists $(\mathrm{n}=11)$ [41]. Vitamin $\mathrm{K}$ antagonist reversal was indicated due to bleeding or the need for 
Table 3. Selected Reports of PCC Use in Infants and Children

\begin{tabular}{|c|c|c|}
\hline $\begin{array}{l}\text { Author and } \\
\text { reference }\end{array}$ & Study design and cohort & Outcomes \\
\hline $\begin{array}{l}\text { Karube et } \\
\text { al [41] }\end{array}$ & $\begin{array}{l}\text { The study cohort included } 24 \text { patients, } \\
\text { ranging in age from } 2 \text { months to } 23 \text { years. } \\
\text { Only two patients were receiving chronic } \\
\text { therapy with anticoagulant medications } \\
\text { (warfarin or enoxaparin). }\end{array}$ & $\begin{array}{l}\text { Twenty-nine doses of } 4 \mathrm{~F}-\mathrm{PCC} \text { at a median dose of } 27 \text { units } / \mathrm{kg} \text {. The primary } \\
\text { indication for PCC administration was perioperative/procedural correction } \\
\text { of coagulopathy. } 4 \mathrm{~F}-\mathrm{PCC} \text { decreased the INR, corrected abnormalities on the } \\
\text { ROTEM, and controlled bleeding. Thrombotic complications (DVT) were noted } \\
\text { in five patients }(20.8 \%) \text { in association with a femoral CVC. }\end{array}$ \\
\hline $\begin{array}{l}\text { Rech et } \\
\text { al [43] }\end{array}$ & $\begin{array}{l}\text { A 5-month-old infant with shock and liver } \\
\text { failure following non-accidental trauma. }\end{array}$ & $\begin{array}{l}\text { Due to bleeding during a laparotomy related to coagulopathy, unresponsive to } \\
\text { platelet and FFP transfusions, PCC ( } 30 \mathrm{IU} / \mathrm{kg} \text { ) was administered. The authors } \\
\text { reported a cessation of bleeding and a decrease of the INR from } 2.9 \text { to } 1.5 \text {. }\end{array}$ \\
\hline
\end{tabular}

PCC: prothrombin complex concentrate; INR: international normalized ratio; DVT: deep vein thrombosis; CVC: central venous catheter; FFP: fresh frozen plasma; ROTEM: rotational thrombo-elastogram.

an urgent surgical intervention. Dosing was based on an institutional guideline that included both weight and the presenting INR. Nine of the 11 patients receiving PCC for vitamin K antagonist reversal had a post-dose INR drawn and all nine demonstrated a rapid and marked improvement in the INR. The authors concluded that within study limitations, when used for the reversal of vitamin $\mathrm{K}$ antagonists, the efficacy and safety of PCCs in infants and children appear to be similar to those reported in adults. Additional single case reports have outlined the use of PCCs to treat dilutional coagulopathy and persistent intra-abdominal bleeding following a laparotomy despite the administration of large volumes of blood products in a 5-month-old infant with shock and liver failure following nonaccidental trauma and to correct coagulopathy in a 6-week-old infant with an intracerebral hemorrhage who did receive vitamin $\mathrm{K}$ prophylaxis at birth $[42,43]$.

\section{Preliminary Experience in Pediatric Patients During Cardiac Surgery}

As with the adult literature, much of the data in the pediatric population regarding PCC use during cardiac surgery include retrospective reports or anecdotal case reports or case series. Two different groups of investigators have provided excellent reviews of the available literature regarding use of PCC and factor concentrates during cardiac surgery in infants and children $[7,13]$. The previously discussed case series of Noga et al, published in 2016, is one of the first series to included pediatric cardiac surgical patients as they described the use of PCC to reverse vitamin $\mathrm{K}$ antagonists prior to cardiac transplantation in 11 pediatric patients and its use to treat refractory bleeding and coagulation disturbances following cardiac surgery and $\mathrm{CPB}$ in an additional five patients [41]. As in the non-cardiac surgical population, reports from the pediatric cardiac surgical population have included patients of all ages from neonates to adolescence (Table 4) [44-49]. The patient population, indications, dosing, use of blood products prior to the administration of PCCs, and the outcome variables have been somewhat varied among these reports. In general, PCCs have been administered to reverse vitamin $\mathrm{K}$ antagonists prior to cardiac surgery or to treat refractory coagulation disturbances with clinically significant bleeding following cardiac surgery and the use of CPB. Although the outcome parameters, specific product used, and dosing schemes have varied and the data derived from retrospective or non-controlled studies, PCCs have generally been reported to be effective in reversing abnormalities noted on laboratory assays of coagulation function and controlling clinical bleeding. In a propensity-matched case-control study, PCCs were noted to be non-inferior to FFP, leading the authors to suggest its use instead of FFP to correct coagulation from cardiac surgery and $\mathrm{CPB}$ in neonates and infants.

\section{Summary}

Coagulation disturbances are seen in various clinical scenarios related to inherited or acquired disorders of coagulation function. Clinically significant coagulation disturbances are frequently seen in critically ill children, following traumatic injuries, during massive transfusions, and following CPB and surgery for congenital heart disease. In most circumstances, laboratory parameter guided therapies using blood and blood products are effective in correcting these abnormalities. The PCC formulations including 3F-PCC, 4F-PCC, and FEIBA have been used mainly in the adult population with sporadic case series and anecdotal reports in the pediatric population. PCCs were first used clinically in patients with hemophilia A and $B$ to replenish factor IX or in patients with inhibitors to factor VIII. They are currently FDA-approved for use in adults 
Table 4. Selected Reports of PCC Use in Infants and Children Undergoing Cardiac Surgery

\begin{tabular}{|c|c|c|}
\hline Author and reference & Study design and cohort & Outcomes \\
\hline Giorni et al [47] & $\begin{array}{l}\text { Retrospective study cohort of } 14 \text { patients, } \\
\text { ranging in age from } 8 \text { to } 67 \text { days, compared } \\
\text { to } 11 \text { case-matched controls. }\end{array}$ & $\begin{array}{l}\text { PCCs administered after CPB. PCC patients had } \\
\text { lower chest tube output in the first } 24 \text { postoperative } \\
\text { hours and decreased transfusion requirements } \\
\text { although these did not reach statistical significance. }\end{array}$ \\
\hline Navaratnam et al [48] & $\begin{array}{l}\text { Five patients, ranging in age from } 7 \text { to } 23 \text { years, } \\
\text { for combined liver-heart transplantation. }\end{array}$ & $\begin{array}{l}\text { PCCs used as part of their perioperative management } \\
\text { protocol following large volume transfusions (1-3 } \\
\text { blood volumes). Four of the five patients also } \\
\text { received an antifibrinolytic agent and rFVIIa. }\end{array}$ \\
\hline Rybka et al [49] & $\begin{array}{l}\text { Prospective cohort of } 15 \text { children, } 9 \text { months to } \\
3 \text { years of age. PCC dosing of } 30-50 \mathrm{IU} / \mathrm{kg} \text {. }\end{array}$ & $\begin{array}{l}\text { Clinical bleeding after heparin reversal with protamine. } \\
\text { Clinical hemostasis was achieved in } 13 \text { of } 15 \text { patients. }\end{array}$ \\
\hline Jooste et al [50] & Retrospective cohort of five neonates and one infant. & $\begin{array}{l}\text { 3F-PCC used in conjunction with rFVIIa (four patients) } \\
\text { and AT-III replacement if level was less than } 70 \% \text {. } \\
\text { Thrombotic complications noted in two patients. }\end{array}$ \\
\hline
\end{tabular}

PCC: prothrombin complex concentrate; CPB: cardiopulmonary bypass; rFVIla: recombinant activated factor VII; AT-III: anti-thrombin III; FFP: fresh frozen plasma; FC: fibrinogen concentrate.

to reverse vitamin $\mathrm{K}$ antagonists in patients with clinically significant bleeding or those requiring emergent surgery. Their use has been reported anecdotally to treat bleeding or as an adjunct to normalize coagulation function in various clinical scenarios in both the adult and pediatric population. Postulated advantages of PCCs over FFP include the absence of the need for ABO typing, a short preparation time, a negligible risk for adverse effects commonly ascribed to FFP including viral transmission, transfusion-associated circulatory overload, and transfusion-related acute lung injury (Table 5) [15, 50].

The main disadvantages of PCCs are a relatively high cost compared to standard therapy with FFP and the potential for adverse effects including thromboembolic effects.

The cost-benefit of 4F-PCC also remains equivocal and difficult to ascertain given varying acquisition costs based on state and even country of use. Joseph et al previously noted that in adult trauma patients, PCC and FFP use compared to FFP use alone was associated with a higher cost of therapy, but a lower overall cost of transfusion [30]. In the United States of America, 4F-PCC is available in vials containing 500 units and 1,000 units and the average wholesale price is approximately $\$ 1.50-1.75$. Cost of a single dose of $25 \mathrm{U} / \mathrm{kg}$ for a $20-\mathrm{kg}$ patient would be approximately $\$ 750-875$ (one 500 unit vial). The cost is further impacted by variations in dosing strategy and whether single or multiple doses are used. The impact of the cost is also affected when the product is used off-label as reimbursement from insurance companies may vary or be lacking, leaving the cost resting on the hospital or even the patient. The cost may limit its universal use outside of specific clinical indications. When the economic impact is evaluated, the other costs of care must be considered including the cost of allogeneic blood products, need for repeated testing, cost of

Table 5. Potential Benefits of PCC Compared to Standard Allogeneic Blood Products

1. General efficacy even in refractory coagulation disturbances

2. No need for specific type and cross matching of product

3. Rapid preparation time

4. Low volume with short administration time

5. Rapid preparation time and rapid administration time lead to rapid correction of coagulation disturbances

6. Limited risk of adverse effects which may be seen with allogeneic blood products including:
a. Viral disease transmission
b. Transfusion-associated circulatory overload
c. Transfusion-related acute lung injury
d. Hemodynamic effects due to effects on ionized calcium
e. Immune and non-immune-mediated transfusion reactions

PCC: prothrombin complex concentrate. 
differences in outcome including ICU stay and length of hospitalization. Most importantly, true outcome measures including mortality need to be clearly evaluated.

Definitive identification of the true risk of thromboembolic events and potential risk factors will require additional prospective data. It has been postulated that the risk of thromboembolic effects may be lower with newer preparations which contain varying quantities of proteins $\mathrm{S}, \mathrm{C}$, and heparin. Given the retrospective and anecdotal nature of most of the reported literature, definitive dosing guidelines are difficult to determine. As the product was originally derived to provide an exogenous source for factor IX replacement, dosing is based on the factor IX concentrations of the product, varying from 25 to $50 \mathrm{IU} / \mathrm{kg}$. Some have recommended dose titration based on the INR with higher doses for a baseline INR $\geq 3$. As future trials are considered, dose escalation studies evaluating varying dosing regimens (low versus high dose) also appear indicated. In the setting of their current applications, factors II and $\mathrm{X}$ are generally the most impacted factors that require the highest degree of correction $[51,52]$. Aside from following routine coagulation parameters such as the INR or prothrombin time, more precise monitors of coagulation function such as the ROTEM or thrombin generation assays may be a more appropriate means for demonstrating clinical outcomes and efficacy. With these caveats in mind, given its potential advantages over FFP especially in critically ill patients where rapid correction of coagulation disturbances may be indicated and the potentials for adverse effects with FFP are high, future randomized trials are warranted to identify its indication, dosing regimens, and applications in the pediatric population.

\section{Acknowledgments}

None to declare.

\section{Financial Disclosure}

None to declare.

\section{Conflict of Interest}

None to declare.

\section{Author Contributions}

Dolly Munlemvo wrote the initial draft and undertook revisions based on the review, edits, and suggestions of Joseph Tobias, Kristin Chenault, and Aymen Naguib.

\section{Data Availability}

The data supporting the findings of this review are available from the corresponding author upon reasonable request.

\section{References}

1. Cholette JM, Faraoni D, Goobie SM, Ferraris V, Hassan N. Patient blood management in pediatric cardiac surgery: a review. Anesth Analg. 2018;127(4):1002-1016.

2. Agarwal HS, Wolfram KB, Saville BR, Donahue BS, Bichell DP. Postoperative complications and association with outcomes in pediatric cardiac surgery. J Thorac Cardiovasc Surg. 2014;148(2):609-616.e601.

3. Guzzetta NA, Allen NN, Wilson EC, Foster GS, Ehrlich $\mathrm{AC}$, Miller BE. Excessive postoperative bleeding and outcomes in neonates undergoing cardiopulmonary bypass. Anesth Analg. 2015;120(2):405-410.

4. Eaton MP, Iannoli EM. Coagulation considerations for infants and children undergoing cardiopulmonary bypass. Paediatr Anaesth. 2011;21(1):31-42.

5. Willems A, Patte P, De Groote F, Van der Linden P. Cyanotic heart disease is an independent predicting factor for fresh frozen plasma and platelet transfusion after cardiac surgery. Transfus Apher Sci. 2019;58(3):304-309.

6. Ghadimi K, Levy JH, Welsby IJ. Prothrombin Complex Concentrates for Bleeding in the Perioperative Setting. Anesth Analg. 2016;122(5):1287-1300.

7. Ashikhmina E, Said S, Smith MM, Rodriguez V, Oliver WC, Jr., Nuttall GA, Dearani JA, et al. Prothrombin complex concentrates in pediatric cardiac surgery: the current state and the future. Ann Thorac Surg. 2017;104(4):14231431.

8. Guzzetta NA, Russell IA, Williams GD. Review of the offlabel use of recombinant activated factor VII in pediatric cardiac surgery patients. Anesth Analg. 2012;115(2):364378.

9. Faraoni D, Meier J, New HV, Van der Linden PJ, Hunt BJ. Patient blood management for neonates and children undergoing cardiac surgery: 2019 NATA guidelines. J Cardiothorac Vasc Anesth. 2019;33(12):3249-3263.

10. Nascimento B, Goodnough LT, Levy JH. Cryoprecipitate therapy. Br J Anaesth. 2014;113(6):922-934.

11. Hedner U. Factor VIIa in the treatment of haemophilia. Blood Coagul Fibrinolysis. 1990;1(3):307-317.

12. Powell JS. Recombinant factor VIII in the management of hemophilia A: current use and future promise. Ther Clin Risk Manag. 2009;5(2):391-402.

13. Guzzetta NA, Williams GD. Current use of factor concentrates in pediatric cardiac anesthesia. Paediatr Anaesth. 2017;27(7):678-687.

14. Sjamsoedin LJ, Heijnen L, Mauser-Bunschoten EP, van Geijlswijk JL, van Houwelingen $\mathrm{H}$, van Asten P, Sixma JJ. The effect of activated prothrombin-complex concentrate (FEIBA) on joint and muscle bleeding in patients with hemophilia A and antibodies to factor VIII. A double-blind clinical trial. N Engl J Med. 1981;305(13):717721.

15. Franchini M, Lippi G. Prothrombin complex concentrates: an update. Blood Transfus. 2010;8(3):149-154.

16. Grottke O, Levy JH. Prothrombin complex concentrates in trauma and perioperative bleeding. Anesthesiology. 2015;122(4):923-931. 
17. Baglin TP, Keeling DM, Watson HG, British Committee for Standards in $\mathrm{H}$. Guidelines on oral anticoagulation (warfarin): third edition-2005 update. Br J Haematol. 2006;132(3):277-285.

18. Goldstein JN, Refaai MA, Milling TJ, Jr., Lewis B, Goldberg-Alberts R, Hug BA, Sarode R. Four-factor prothrombin complex concentrate versus plasma for rapid vitamin $\mathrm{K}$ antagonist reversal in patients needing urgent surgical or invasive interventions: a phase $3 \mathrm{~b}$, open-label, non-inferiority, randomised trial. Lancet. 2015;385(9982):20772087.

19. Mishra AK, Sahu KK, Lal A, George SV. Factors contributing to poor outcome in patients on warfarin receiving 4-factor prothrombin complex concentrate in critically ill. Acta Biomed. 2021;92(5):e2021281.

20. Choi Q, Kim JE, Hyun J, Han KS, Kim HK. Contributions of procoagulants and anticoagulants to the international normalized ratio and thrombin generation assay in patients treated with warfarin: potential role of protein $Z$ as a powerful determinant of coagulation assays. Thromb Res. 2013;132(1):e70-75.

21. Holland L, Warkentin TE, Refaai M, Crowther MA, Johnston MA, Sarode R. Suboptimal effect of a three-factor prothrombin complex concentrate (Profilnine-SD) in correcting supratherapeutic international normalized ratio due to warfarin overdose. Transfusion. 2009;49(6):11711177.

22. Bruce D, Nokes TJ. Prothrombin complex concentrate (Beriplex $\mathrm{P} / \mathrm{N}$ ) in severe bleeding: experience in a large tertiary hospital. Crit Care. 2008;12(4):R105.

23. Fries D, Haas T, Klingler A, Streif W, Klima G, Martini $\mathrm{J}$, Wagner-Berger $\mathrm{H}$, et al. Efficacy of fibrinogen and prothrombin complex concentrate used to reverse dilutional coagulopathy - a porcine model. Br J Anaesth. 2006;97(4):460-467.

24. Dickneite G, Doerr B, Kaspereit F. Characterization of the coagulation deficit in porcine dilutional coagulopathy and substitution with a prothrombin complex concentrate. Anesth Analg. 2008;106(4):1070-1077.

25. Dickneite G, Pragst I. Prothrombin complex concentrate vs fresh frozen plasma for reversal of dilutional coagulopathy in a porcine trauma model. Br J Anaesth. 2009;102(3):345-354.

26. Pragst I, Kaspereit F, Dorr B, Dickneite G. Prothrombin complex concentrate (Beriplex $\mathrm{P} / \mathrm{N}$ ) for control of bleeding after kidney trauma in a rabbit dilutional coagulopathy model. Thromb Res. 2010;125(3):272-277.

27. Rossaint R, Cerny V, Coats TJ, Duranteau J, FernandezMondejar E, Gordini G, Stahel PF, et al. Key issues in advanced bleeding care in trauma. Shock. 2006;26(4):322331.

28. Spahn DR, Bouillon B, Cerny V, Duranteau J, Filipescu D, Hunt BJ, Komadina R, et al. The European guideline on management of major bleeding and coagulopathy following trauma: fifth edition. Crit Care. 2019;23(1):98.

29. Joseph B, Hadjizacharia P, Aziz H, Kulvatunyou N, Tang A, Pandit V, Wynne J, et al. Prothrombin complex concentrate: an effective therapy in reversing the coagulopathy of traumatic brain injury. J Trauma Acute Care Surg.
2013;74(1):248-253.

30. Joseph B, Aziz H, Pandit V, Hays D, Kulvatunyou N, Yousuf Z, Tang A, et al. Prothrombin complex concentrate versus fresh-frozen plasma for reversal of coagulopathy of trauma: is there a difference? World J Surg. 2014;38(8):1875-1881.

31. Zeeshan M, Hamidi M, Kulvatunyou N, Jehan F, O'Keeffe T, Khan M, Rashdan L, et al. 3-Factor versus 4-factor PCC in coagulopathy of trauma: four is better than three. Shock. 2019;52(1):23-28.

32. Joseph B, Aziz H, Pandit V, Hays D, Kulvatunyou N, Tang A, Wynne J, et al. Prothrombin complex concentrate use in coagulopathy of lethal brain injuries increases organ donation. Am Surg. 2014;80(4):335-338.

33. Joseph B, Pandit V, Khalil M, Kulvatunyou N, Aziz H, Tang A, O'Keeffe T, et al. Use of prothrombin complex concentrate as an adjunct to fresh frozen plasma shortens time to craniotomy in traumatic brain injury patients. Neurosurgery. 2015;76(5):601-607; discussion 607.

34. Ortmann E, Besser MW, Sharples LD, Gerrard C, Berman M, Jenkins DP, Klein AA. An exploratory cohort study comparing prothrombin complex concentrate and fresh frozen plasma for the treatment of coagulopathy after complex cardiac surgery. Anesth Analg. 2015;121(1):2633.

35. Gorlinger K, Dirkmann D, Hanke AA, Kamler M, Kottenberg E, Thielmann M, Jakob H, et al. First-line therapy with coagulation factor concentrates combined with point-of-care coagulation testing is associated with decreased allogeneic blood transfusion in cardiovascular surgery: a retrospective, single-center cohort study. Anesthesiology. 2011;115(6):1179-1191.

36. Arnekian V, Camous J, Fattal S, Rezaiguia-Delclaux S, Nottin R, Stephan F. Use of prothrombin complex concentrate for excessive bleeding after cardiac surgery. Interact Cardiovasc Thorac Surg. 2012;15(3):382-389.

37. Enter DH, Zaki AL, Marsh M, Cool N, Kruse J, Li Z, Andrei AC, et al. Prothrombin Complex Concentrate Reduces Blood Product Utilization in Heart Transplantation. Pharmacotherapy. 2017;37(10):1215-1220.

38. Roman M, Biancari F, Ahmed AB, Agarwal S, Hadjinikolaou L, Al-Sarraf A, Tsang G, et al. Prothrombin complex concentrate in cardiac surgery: a systematic review and meta-analysis. Ann Thorac Surg. 2019;107(4):1275-1283.

39. Leissinger CA, Becton DL, Ewing NP, Valentino LA. Prophylactic treatment with activated prothrombin complex concentrate (FEIBA) reduces the frequency of bleeding episodes in paediatric patients with haemophilia A and inhibitors. Haemophilia. 2007;13(3):249-255.

40. Karube T, Andersen C, Tobias JD. Single-Center Use of Prothrombin Complex Concentrate in Pediatric Patients. J Pediatr Intensive Care. 2020;9(2):106-112.

41. Noga T, Bruce AA, Blain H, Nahirniak S. Four-factor prothrombin complex concentrates in paediatric patients - a retrospective case series. Vox Sang. 2016;110(3):253257.

42. Rech MA, Wittekindt L, Friedman SD, Kling K, Ubogy D. Prothrombin complex concentrate for intracerebral 
hemorrhage secondary to vitamin $\mathrm{K}$ deficiency bleeding in a 6-week-old child. J Pediatr. 2015;167(6):1443-1444.

43. Fuentes-Garcia D, Hernandez-Palazon J, SansanoSanchez T, Acosta-Villegas F. Prothrombin complex concentrate in the treatment of multitransfusion dilutional coagulopathy in a paediatric patient. Br J Anaesth. 2011;106(6):912-913.

44. Giorni C, Ricci Z, Iodice F, Garisto C, Favia I, Polito A, Carotti A, et al. Use of Confidex to control perioperative bleeding in pediatric heart surgery: prospective cohort study. Pediatr Cardiol. 2014;35(2):208-214.

45. Navaratnam M, Ng A, Williams GD, Maeda K, Mendoza JM, Concepcion W, Hollander SA, et al. Perioperative management of pediatric en-bloc combined heartliver transplants: a case series review. Paediatr Anaesth. 2016;26(10):976-986.

46. Rybka MM, Samsonova NN, Klimovich LG, Rogalskaya EA, Khichagov DY, Tataryan FE. [Correction of Hemostasis with Blood Products in the Surgical Treatment of Congenital Heart Disease in Infants and Young Children]. Anesteziol Reanimatol. 2015;60(5):42-46.

47. Jooste EH, Machovec KA, Einhorn LM, Ames WA, Homi HM, Jaquiss RD, Lodge AJ, et al. 3-Factor Prothrombin Complex Concentrates in Infants With Refractory Bleed- ing After Cardiac Surgery. J Cardiothorac Vasc Anesth. 2016;30(6):1627-1631.

48. Sisti DJ, Williams GD, Ding V, Long J, Maeda K, Chen $\mathrm{S}$, Navaratnam $\mathrm{M}$. The use of prothrombin complex concentrate as a warfarin reversal agent in pediatric patients undergoing orthotopic heart transplantation. Paediatr Anaesth. 2020;30(5):564-570.

49. Velik-Salchner C, Tauber H, Rastner V, Pajk W, Mittermayr M, Wally D, Kilo J, et al. Administration of fibrinogen concentrate combined with prothrombin complex maintains hemostasis in children undergoing congenital heart repair (a long-term propensity score-matched study). Acta Anaesthesiol Scand. 2021;65(9):1178-1186.

50. Samama CM. Prothrombin complex concentrates: a brief review. Eur J Anaesthesiol. 2008;25(10):784-789.

51. Faraoni D, Willems A, Romlin BS, Belisle S, Van der Linden P. Development of a specific algorithm to guide haemostatic therapy in children undergoing cardiac surgery: a single-centre retrospective study. Eur J Anaesthesiol. 2015;32(5):320-329.

52. Varadi K, Negrier C, Berntorp E, Astermark J, Bordet JC, Morfini M, Linari S, et al. Monitoring the bioavailability of FEIBA with a thrombin generation assay. J Thromb Haemost. 2003;1(11):2374-2380. 